\title{
Refocusing group work on collaborative learning and diversifying assessments in political science departments
}

\author{
Oana Burcu \\ School of Politics and International Relations \\ University of Nottingham, UK \\ NG7 2RD \\ Email: Oana.burcu@nottingham.ac.uk
}

\begin{abstract}
Group work is an essential aspect of our personal, educational and professional development, yet it is not a common method of assessment in Politics and International Relations departments at British Universities. This study explores how instructors can effectively engage students in assessed group work to help them develop an appropriate mix of skills by focusing on collaborative learning and scaffolding. It draws on primary sources collected from a final year Politics and International Relations module at a top-ranking British University. Group work assessment is discussed in relation to three points of comparison: cooperative and collaborative learning, formative and summative assessment, and individual and group achievement rates. The key findings suggest that a) students have the ability to learn collaboratively with minimum "scaffolding" in place and prefer being empowered to self-manage their respective groups and arising problems and b) formative group assignments and intermediary feedback are perceived by students as key in supporting group performance. The findings and proposed recommendations provide a guide for educators interested in diversifying their assessment methods and supporting students' development.
\end{abstract}


Keywords assessment $\cdot$ collaborative learning $\cdot$ group work $\cdot$ scaffolding

\section{Introduction}

Group activities are an indispensable part of our development. From an early age we engage in group play which over time teaches us how to navigate the intricacies of a much more complex social system. Throughout the education system, from primary school to university, we further engage in group activities and develop a wide range of skills such as communication and critical thinking (Gokhale, 1995), enhanced information retention and deepened learning (Oakley et al., 2004) and ability to tackle more challenging tasks (Gibbs, 2009). Group work not only contributes to students' personal development and their learning experience, but it also prepares them for their future professional life by allowing them to play to their strengths and better their weaknesses, developing professional accountability, as well as tolerance and respect for each other (Mello, 1993; Jaques, 2000; Ruel et al. 2003; Dolmans et al. 2001; Bourner et al. 2001; Maguire and Edmondson 2001; Johnson, and Smith, 2007). As universities are one of the most important training grounds for students' preparedness for employment, group work is set to bear some resemblance to a collaborative working environment and social situations with the aim of developing an array of skills.

This article brings to the fore novel discussions on collaborative learning by analysing how students work in groups and what can be improved in their practice. To tackle these issues, the article first provides a brief review of the literature on group work, with a focus on cooperative and collaborative learning, arguing that it is important to distinguish between these often conflated terms that sit at the crux of the group work process. It then moves to scaffolding, defined as the academic staff support that students need to improve their understanding and become better and more independent learners; this discussion frames the analysis of how students work most effectively in groups. This is followed by a methodological discussion, findings and recommendations that add value to the traditional group work setup. 


\section{Literature review}

Since the late 1980s a considerable amount of literature has been published on the importance of group work in the higher education system. Scholars have given prominence to a host of skills that group work offers students (Colbeck et al., 2000; Livingstone and Lynch, 2000; Michaelsen, 1992; Cumming, 2010; Hobson et al., 2014, Cumming et al., 2015) and the problems that students face while working in groups (Pauli et al., 2008; Walker, 2001; Freeman and Greencare, 2011; Maiden and Perry, 2011). Group work research has continued to become more elaborate with studies delving into group work design such as group forming mechanisms (Webb et al., 2002), devising disjunctive or conjunctive tasks (Curşeu et al., 2011), and providing a fairer method of assessment that often includes a peer review element (Pfaff and Huddleston, 2003; Erez et al., 2002; Oakely et al., 2004).

Despite the plethora of research conducted over the last three decades, to date there has been little agreement over the meaning of collaborative and cooperative learning and how students work more effectively. Some studies do not use both terms but clearly differentiate between different types of learning carried out in groups. Johnson and Johnson (1999), in one of the key studies in this field, differentiate between "pseudo-learning groups" where students see each other as competitors and obstruct each other's learning, "traditional classroom learning group" where little joint work is required and students minimise sharing and helping, and a "(high performance) cooperative learning classroom" where students seek each other's support because they realise that they will perform better as a group than individually and are highly committed to it. Smith (1996: 74) pushes Johnsons' latter category forward when he claims that cooperative learning should not be about stronger students compensating for the weaker ones and only sharing and discussing materials, but it is about building interdependence, interaction, accountability, developing team skills and the ability to evaluate their group productivity. In today's language, this understanding comes close to what other 
scholars would define collaborative learning (Barkley et al., 2014), hence the conflation between the two words.

Collaboration is a process in which two or more persons plan, implement, and evaluate a project together [emphasis added] (Jorn and Duin, 1992). This implies that the team is involved in all the production stages of the project and solve the task together by being engaged in the process of sharing and creating knowledge. Joint knowledge creation means that the development of knowledge and understanding is being influenced by the views of the other team members which are constantly shared and negotiated through discussions. To some extent this sits in contrast to cooperative learning where the group splits a task into subtasks and each participant is responsible for doing their part, keeping interaction and active discussions among group members at a minimum. While in cooperative learning students may also draw on each other's ideas, this is usually marginal, as group members are more likely to passively accept information received from their peers, rather than debating and evaluating it. In other words, cooperative learning lacks the interactivity and creativity of collaborative learning (Hämäläinen and Vähäsantanen, 2011). Collaborative work offers students opportunities to take clearer charge of their projects as co-producers of knowledge.

Collaborative group work also lends itself to the universal design for learning (Rose and Meyer, 2002) that aims to accommodate the needs, interests, strengths and weakness of every student and eliminate barriers in the learning process. This implies the curriculum content being presented to students in different forms, providing the necessary opportunities for students to engage in learning and diversifying the ways in which they can demonstrate their learning. First, students are likely to be more resourceful when working in groups towards a project as they get to share multiple types of materials that each member of the group has researched, potentially going beyond those proposed by the instructor. Second, engagement can be triggered not only by the instructor, but by their own group peers who may highlight the 
relevance and value of a topic in a different and potentially more incentivising manner, fostering collaboration and community can optimise motivation. Third, the frequent meetings outside seminars and lectures required for the successful completion of the group project provide more opportunities for students to express themselves and contribute in different ways to the outcome.

This approach to collaborative group work is best understood through the constructivist epistemological tradition. Constructivists believe that reality is produced and understood through interchanges between people, shared objects and activities as individuals create and experience meaning together. Collaborative group work meets Vygotsky's social development theory (1978) criteria through social interaction, collective and individual learning components, the importance of "more knowledgeable" peers to the construction of knowledge where each play to their strengths, and the realisation that through collaboration a task can be tackled more extensively.

However, students' ability to engage effectively in group work has been questioned. Rafferty argues that students' group work skills are overestimated often due to feelings of apprehension about distribution of tasks, cultural uncertainty and problems of logistics, requiring instructors to guide desirable group behaviours and norms (Rafferty, 2012). In a separate experiment on peer learning group, where students were asked to tackle weekly group tasks in preparation for the coming lecture and the end of term assignment, Schedlitzky and Witney (2014) find that students are unable to work independently, partially due to the flexibility of engaging face to face and online, and the lack of value they allocated to empowerment as learners and contributors to content. The question that then arises is whether students can work collaboratively and have the skills to do so or is it an assumption that instructors often make but needs to be rectified by offering students the right amount of support? This is even more important as it has been shown that the students' perception of 
academics being too detached from group problems affects their performance and satisfaction (Bonanno et al., 1998; Chapman and Van Auken, 2001). The concept of "scaffolding" proves helpful in this conundrum. Stratling et al. (2018: 4) define scaffolding as "a dynamic intervention provided to facilitate and be responsive to students' learning progress". Since scaffolding has gained currency over the years, it has been used to describe a holistic "integration of multiple resources (experts, peers, technologies, and learning context)" (Kim and Hannafin, 2011). However, this article goes back to the original understanding of scaffolding in education defined as the "temporary, but essential, nature of the mentor's assistance as the learner advances in knowledge and understanding" (Maybin et al., 1992: 186). Recent studies point out that students working in groups require substantial "scaffolding" by setting interim targets and timetables or requiring students to write progress reports (Stratling et al., 2018). One potential concern with too much scaffolding is the extent to which this takes away from students the opportunity to acquire skills that group work is supposed to provide; for example, close monitoring of multiple deadlines or conflict solving can take away from opportunities to develop project management skills.

This article first sets group work assessment into context by providing an overview of how often it is used in a sample of highly ranked British universities. It then explains the methods used to collect the data before moving onto findings. This is followed by two assessments, one of whether students can work collaboratively, which maintains focus on peer feedback and a minimal level of scaffolding, and one on the degree of scaffolding students prefer.

\section{Group work assessment in Politics and IR departments}

When looking both at module handbooks and at the employability frameworks that career centres within universities issue, team work skill is the common denominator. Module handbooks are informed by the QAA subject benchmark for the Politics and International 
Relations discipline (2015). According to the latest version of the document, the concept of "group work" and "team work has" 10 occurrences in total, under the sections of "Teaching and learning approaches" and "Assessment". It stresses the ways through which graduates should "collaborate with others to achieve common goals through, for example, group work, group projects, and group presentations" in order to become better prepared for professional life: "employers regard collaboration and the identification of common goals highly. This is especially so as public sector organisations and other agencies increasingly work together, and multi-agency teams are developed" (QAA, 2015: 13).

Indeed, the importance of group work in employment has been highlighted particularly in the post-Fordist period of the late $20^{\text {th }}$ century when team structures became common in the workplace. Collaborative work was encouraged as the practice of teamwork was associated with an increase in productivity (Cappelli and Neumark, 2001: 742). Since the mid-1990s, with a further changing global economic environment, employers have focused on the "the ability to work collaboratively as requisite to success" (Lookatch, 1996). Two decades later, communication, cooperation and team work remain one of the most sought-after qualities by employers. In a survey conducted by Ashridge Business School of 600 organisations from around the world, 75 per cent of their teams are spread geographically, 30 per cent are also spread across time zones, and half are "virtual" and "rarely met", indicating the importance of teamwork, including emotional intelligence, collaborative work and soft skills for employers (Tieman, 2012).

Responsive to the market, career centres within universities emphasise the importance of team skills. For example, when analysing the framework for embedding employability in 
higher education from the eight most research-intensive Universities in the North of England ${ }^{1}$, which includes the university where this research was carried out, common elements can be identified. Out of the six skills that appear in all employability frameworks, i.e. commercial awareness, IT skills, communication skills, problem-solving, project management or organisation skills, and teamwork (Perkins, 2018), the latter four can most adequately be achieved through group work.

However, when looking at the group work assessments carried out at the same universities within Politics and International Relations departments, the numbers are generally low, with the exception of University of Manchester. A brief indication of this practice is provided in the table below.

\section{Table 1 here}

Despite the expectation that students will develop teamwork skills at university, group assessment is not a common method in Politics and International Relations departments in some of the top British Universities sampled. Moreover, there is a concern in the wider literature that even when group work is employed as a means of assessment, only a few pay particular attention to developing students' teamwork knowledge and skills (Hansen, 2006) and enhancing the group experience overall (Chapman and Van Auken, 2001).

\section{Methods}

The sample of this study comprises of 46 students enrolled in a third-year module that the author convened in a Politics and International Relations department from a highly ranked British university. This was a one year-long module, optional and from the area studies field.

\footnotetext{
${ }^{1}$ N8 Research Partnership is a not-for-profit organisation funded by eight member universities from the North of England, to promote deeper collaboration between universities, business and society, drive innovative research and regional economic growth.
} 
The module assessment had three components, a formative and summative essay group component, scrutinised in this article, and an individual essay component.

Research indicates that while students prefer to choose their own groups (Osmond and Roed, 2010), these tend to gravitate around friendships and are not as effective as groups selected by the teaching staff (Felder and Brent, 2001) based on performance levels, academic strengths and weaknesses, ethnicity and gender (Connery, 1988). While in this study groups were formed based on some of Connery's features such as ethnicity and gender, including whether students were native English speakers and have learning disabilities, for a new tutor students' academic strengths and weaknesses can be difficult to grasp at the beginning of the module. In hindsight, a better way for an instructor unfamiliar with the students is to highlight a number of skills that a group requires to accomplish a particular task and then ask students to identify their skills and then form groups accordingly (Rafferty, 2012). The cohort of students had a gender split of 57 per cent female and 43 per cent men and diversity split of 64 per cent British and 36 per cent non-British students, both of which was reflected in the composition of groups. The study relies on three primary sources. First, it uses 47 peer evaluation forms submitted part of the summative assessment inform this article. In these forms students were asked to define their group work process, including their own contribution to it, and to mark each of their peer's effort. The peer grade represented 33 per cent of their group summative grade, while the rest of 67 per cent came from the essay the group produced. These forms shed light on group dynamics. Second, semi-structured interviews were conducted with nine participants, each representing one of the 14 groups. Each group generally included three or four members, except for four groups of two which were formed due to drop outs or small seminar groups. Interviewing the remaining five groups was restricted by delays caused by ethical approvals vis-à-vis the new EU General Data Protection Regulation (GDPR) and the graduation of interviewees. Otherwise, further interviews for each of the remaining groups and 
surveys for the entire sample drawing on existent group work survey models (Cumming et al. 2015; Gatfield, 1999; Stratling et al., 2018) would have been conducted. Thirdly, the results from both group formative and summative assessment, as well as the individual assessment component are considered. The group component represented 33 per cent of the final grade while the individual component represented the remaining 67 per cent difference. These grades serve as an insight into achievement rates by allowing comparison between formative with summative results, and individual work with group work.

All interviews took place over Skype and phone. The interviews were semi-structured and drew largely on the literature discussed in the previous section. Given that the interviewer also convened and taught the module, potential issues of response bias was considered. This concern was, however, mitigated first by the fact that the interview took place after all participants had graduated. Second, in order to remove power asymmetries potentially eschewing the results, the researcher made herself available for written feedback in case students wanted to complement their oral interview and felt more at ease to do so in indirect interaction. Students were clearly informed about the purpose of the project and the possibility to amend any information provided in the interview or withdraw altogether from the study at any point.

The limitations of this study are foremost related to the relatively small sample of participants and the selection of the sample which draws on one institution only, where the admission bar of the department is set high at three straight As. The influence of the students' background on their behaviour and skills cannot be dismissed either (Renshaw, 2013). Both these limitations make generalisations less suitable despite offering an in-depth view of students' collaborative work. This article can nevertheless serve as a model in the conduct of further research across departments and educational institutions. 


\section{Findings and discussions}

This section presents the findings of the main question "How do students work in groups?", with a focus on collaborative work, feedback and scaffolding.

\section{Collaborative group work}

In order to assess whether students worked collaboratively or not, several indicators derived from the literature review were considered: face-to-face group meetings, online group meetings, tasks undertaken as a group and individually, and peer feedback.

Before moving on, it should be clarified that at the beginning of the module students were provided with simple verbal guidelines about how to operate in groups. They were encouraged to meet in person and get to know each other and not resort solely to online platform; to exchange ideas and engage in debates; to plan well in advance; and to ensure that the overall output is a coherent flowing piece of work. At the same time students were warned about the risks of working separately and simply copying and pasting their individual sections into a bigger article, and about free-riding behaviour. Students were also reminded about the lecturer's availability for any arising issues. These guidelines were repeatedly reinforced throughout the module, both in lectures and seminars. Beyond this advice, there were no constraints on how the groups should operate.

Findings suggest that students often met in person and appreciated the importance of these meetings. From both evaluation forms and interviews, two main lines of arguments emerged. Some pointed out that messages easily got lost in online communication while when meeting in person more topics and issues got covered in a shorter time-span (Interview with G, 2018). Others planned well ahead and booked study rooms in the library to facilitate face to face discussions which covered anything "From simple questions to do with referencing style to more complex issues regarding whether or not we ought to come up with a theoretical concept" (J, 2018). Moreover, on average groups met 8-10 times and a minimum of 4-5 times. 
Those 4 groups that met more and fall within the first category achieved over $70+$, while those who met less scored less. This suggests a positive correlation between meeting face-to-face and grade results; Schedlitzky and Witney (2014: 207) came to a similar conclusion when analysing the responses of $30 \mathrm{MBA}$ students. This finding is worth investigating on a larger scale as it could shape the guidelines on how groups can operate effectively.

Beyond meeting in person, all groups used online platforms to communicate. Social network Facebook was preferred and served as an organising tool for setting meetings and agendas and hence enabled students to manage their time well, as they acknowledged the difficulty of clashing schedules and the need to set timely deadlines to ensure the successful completion of the project. Facebook was also deemed useful for smaller queries such as checking concepts or sections that they were unclear about from their own readings or peers' sections, but not for discussing the assessment in detail. This is in line with other findings showing that Facebook can offer an informal learning space for students (Madge et al., 2009). Additionally, a Google Docs was set up by all groups to coordinate effective writing, feedback and editing; it was described as "an invaluable platform to share literature, comment, criticise and bounce ideas off each other" (L, 2018). Indeed, online learning through Google Docs in this case, in comparison to face-to-face, enabled some students to take their time to compose thoughtful responses and make their voices heard (Kassop, 2003).

By combining face-to-face learning with multiple technological tools, students created a blended learning environment that they self-regulated. Such an environment encourages learners to stay motivated and actively involved, to develop strong organisational skills (Oh and Lim, 2005) and time management skills (Aycock et al., 2002), and to accept "responsibility for constructing meaning and understanding" (Garrison and Kanuka, 2004). Additionally, 
blended learning created the space for asynchronous discussions needed when timetabling was tight, a common issue raised by the students in this study.

Meyer (2003), Garrison and Anderson (2003) argue that students do not value online discussions for developing deep, reflective and meaningful understandings, but this research argues that different platforms were used for different purposes and it is important for instructors to recognise this in order to advise students appropriately and conduct effective group work. While Facebook discussion indeed did not lead to deeply thoughtful discussions, face-to-face discussions throughout the group work process and Google Docs at later stages of the writing process were vital.

In both interviews and peer review forms, students highlighted the importance of collaborative work, i.e. having joint discussions and exchanging feedback to enable them to build an overarching argument. The most common benefit mentioned was the "power of the group", i.e. the usefulness of peer feedback and joint effort in writing and editing, along with the opportunity for deeper and broader topical understandings, exchanging and creating ideas, as well as the development of certain skills. Some of this is captured well by an interviewee who explains that "it was good to have someone to work with on an argument, to give equal attention to an issue as opposed to when working on an individual essay" (Interview with E, 2018). Group power was also often praised for mistakes being more easily flagged up and editing being at a much higher standard than it would have been in an individual assignment (Interview with B, 2018). A European student mentioned her qualms and the peer support received:

I was uncomfortable to ask for help in the first year of university study; I was new to economics and I was too shy to approach lecturers. I didn't know where to turn for help 
(...) I wish group work was more common and introduced earlier than the $3^{\text {rd }}$ year $(\ldots)$

I found group work easier because I could ask for help, bounce ideas around and get feedback. In an individual project, you are the only expert (Interview with H, 2018).

For some, working in groups widened their perspective on the topic tackled and the quality of work:

an individual essay wouldn't have covered as much as in a group work where you get an insight into what others do and is rewarding. The parts of the essay we wrote together were the best ones and you could see the added value of working in groups. (Interview with C, 2018).

Whilst bouncing ideas off each other from the early stages of planning and writing some sections together was characteristic of all groups researched and in line with the expectations of an effective group work, the engagement of students in peer feedback was much lower despite it being an essential element of collaborative work. While in some proportion peer feedback is found in multiple aforementioned activities and stages of the group work process, it is invaluable when students use it to assess each other's individual work part of the conjunctive task, for example. Commenting on each other's work and eventually using the marking criteria to run this informal assessment would be extremely beneficial, but it also is what students are reluctant to do.

Five out of the nine students explicitly described how they engaged in substantial constructive and critical peer-feedback. The first category of students generally described a collaborative process where they shared ideas, raised questions to each other that varied from theoretical concepts to referencing style, wrote sections together and provided comments on each other's written sections. In the words of one of these students the "constructive feedback" received was seen as "the biggest perk of the project (...) we all had different writing styles, 
ideas and approaches to the question, but we made a big effort to listen to each other and bounce off each other's ideas to give the best answer possible" (Interview with D, 2018).

However, four students, despite explaining a satisfactory level of collaborative work undertaken in their individual groups, did not engage in a deeper peer-feedback process. In two instances, students focused more on "language issues and taking out text" (Interview with H, 2018) and ensuring "the line of argumentation does not veer away from the central argument" so that the essay reads as one coherent piece $(\mathrm{R}, 2018)$. Some expected more critical feedback from their group peers, but limited knowledge or exposure to a new topic sometimes made this difficult or simply group members were perceived as too "accommodating" and not sufficiently “critical" (Interview with A, 2018). In another instance, because students "trusted each other" in producing individual sections of the essay to a high standard, only retrospectively, they realised that their article would have benefited from further peer feedback (Interview with C, 2018). Not only that students are missing out on opportunities to provide feedback to each other and improve their group work, but by dividing the tasks between different group members and not critically evaluating them they end up with fragmented knowledge which can defy the purpose of group work.

This finding partly subscribes to some of the criticism expressed in the literature that "insufficient/inappropriate facilitation and structuring of the activities (especially the 'how to' discuss)" and "a misinterpretation of cohort skills" can impede group learning (Schedlitzky and Witney, 2014: 209). Other studies have found a strong positive correlation between interaction, defined as students giving help and offering explanations to their peers, and achievement (Peterson et al., 1981; Webb and Cullian, 1983: 421). All these findings informed the following three recommendations which could help improve peer feedback: 1) instructors should encourage students to review each other's individual sections regularly in a more structured way by providing them with leading questions and brief points extracted from the 
marking criteria grid. Practice can be provided in regular seminars where peer activities which ask students to give each other specific written feedback on small text samples can be integrated; 2) groups should be formed by instructors based on students' skills, hence ensuring assets and liabilities are spread evenly across the groups (Michaelsen, 1994) which are more likely to perform better and remain stable (Koppenhaver and Shrader, 2003). Students eventually value these allocated groups rather than randomly assigned groups or self-selected ones as they get to appreciate the benefits of learning from each other (Rafferty, 2012). 3) group projects should be designed in a way that require "collaboration and synergistic thinking for their successful completion" (Marks and O'Conner, 2013: 157) and makes students realise that they could not have achieved the same positive results by themselves, might innately improve the engagement with peer feedback.

While students have generally shown that they have to some extent the necessary skills to work collaboratively, at times these need to be fostered and guided to maximise the efficiency of group work. This form of guidance, however, does not need to be in the form of substantial monitoring interference, as discussed next.

\section{Scaffolding}

Based on previous research, particularly by drawing on Stratling et al. (2018), the interviewees were asked whether they think they could have benefitted from lecturers 1) monitoring group meeting schedules 2) checking group minutes submitted 3) monitoring Google Docs to follow members' contributions 4) setting intermediary deadlines and/or targets 5) giving each individual group intermediary feedback.

\section{Table 2 here}

Findings suggest that students prefer not to be constrained or monitored in their work due to the perceived interference with potentially negative consequences for the stability of the group. 
None of the students interviewed considered it useful to have their meeting schedules monitored. The common explanation was that at third year level students are used to working on their own and they should have the skills to manage their schedules and organise group work themselves. "It [monitoring group meetings] would defy the purpose of group work. Meetings were spontaneous at times, meeting after lectures or seminars was more productive" (Interview with C, 2018).

Submitting minutes from meetings and allowing the lecturer to have access to the groups' joint Google Docs were also rejected for similar reasons. Most argued that these "scaffolding" measures were an artificial fix, prone to create inaccurate perception students' contributions and more likely to disrupt the flow of the group than to assist it. For instance, the issue of the format and detail of the minutes taken in meetings was a concern, as was the fact that peers may be more likely to withhold sharing ideas and information in informal settings because they would keep them for formal meetings that were minuted or add them on Google Docs to enhance the perception of their individual contribution. There was clearly a concern about these measures giving rise to individualism and competition rather than being conducive to a collective group work. Additionally, students pointed out that some are more active and articulate when writing than when speaking and vice-versa, and some scaffolding measures would put some at a (dis)advantage. However, several students recognised the potential benefit of these checks in minimising free riders, group disputes and recording presence at meetings, but rarely did they think it would have been suitable for their own group. Intermediary targets and deadlines were also received with reluctance. Not only that the idea was not embraced, but different individual timetables and work styles, where some read more broadly before starting to write up, were seen as significant impediments as well. Instead of applying a set of "controlling" measures, as they were often perceived rather than "scaffolding" measures, students suggested to be provided with clearer "guidelines" about an "ideal" number of 
meetings that groups should organise and approximate deadlines that they can use as points of reference to ensure a gradual completion of the project. The optional and yet useful nature of these measures was stressed.

These findings are contrary to those of Stratling et al. which drew upon surveys and interviews with students from the same university but a different department which show that students prefer having interim targets and timetables set, as well as writing progress reports with clear specification of the division of tasks and performance to support direction maintenance (2018). However, the current findings align with those of Stratling et al., as they both highlighted that intermediary group feedback provides students with guidance on how to improve their performance. Numerous other research articles points at the role of feedback in both improving performance and motivating students at an individual level (Beaumont et al., 2011; Ryan and Deci, 2000; Hattie and Timpereley, 2007; Williams and Smith, 2017). The intermediary feedback was the sole suggestion that all interviewees agreed with. There was a clear interest in extra feedback, generally in the form of a feedback session during office hours or as an extra seminar dedicated solely to group work. However, it also comes as somewhat of a surprise given that students had already received feedback on their formatives ${ }^{2}$ and were reminded throughout the term that they can solicit support during office hours, of which approximately just over a third of groups took advantage. Only one of the interviewees recognised formative feedback as a form of intermediary feedback reason for which he did not see the need for adding another layer of feedback half way through the group project (Interview with $\mathrm{D}, 2018)$. While feedback is useful in supporting students, research also shows that students who are less confident in themselves are more likely to ask for frequent feedback

\footnotetext{
${ }^{2}$ The group assessment under scrutiny included both formative and summative elements on non-identical, but similar topics and tasks, so that students could use part of the content and structure of their formative as a basis for the summative assignment. Students often highlighted the importance of formatives in terms of the feedback received, but also familiarising themselves with their peer members and the process of working in a group, managing time better, handling conflicts, increasing motivation levels and setting clearer expectations.
} 
(Knight and Yorke, 2003), which may not be conducive to shaping independent learners. An instructor has to be clear about the importance of engaging with formative feedback and the frequency with which intermediary feedback is provided, judging by the students' ability to deal with a group task, rather than their perceived needs.

The effectiveness of the formative assignment is noticeable when comparing formative and summative group work grades: 11 out of 14 groups achieved higher grades in their summative assignments. In five cases there were significant two-digit differences ranging from 16 to 30 points (see Graph 1). As students often commented in peer review forms and interviews, they worked harder for their summative assignment, motivated by the group work experience and feedback received on their formative assignment. Understandably, not all universities have the capacity of setting up formatives, but then at least some form of intermediary feedback should be made available to students throughout their group work process.

\section{Figure 1 here}

Another good marker of the effectiveness of group work is when comparing the results of individual and group assignments. Despite students' concerns about their grades being lowered by group work, the majority of 66 per cent achieved higher grades in group than individual work. Out of the 15 students who scored less in individual work than groups work, 14 were within the same grading band. In other words, students have a 72 per cent chance of scoring higher in a group effort than they would on their own. Results from another British university that compares undergraduates' perceptions of individual and group assessments also concludes that while "students may instinctively prefer individual assessment (...) they perform best, and achieve greatest perceived development of key skills, in group assessments" (Knight, 2004: 
63). It is this type of finding that should be included in module handbooks to inform students' choices of modules better, given their concerns about group performance.

\section{Figure 2 here}

To sum up, students preferred the independence that a group project offered them; they recognised the wide range of skills employed to make the group project successful and assumed the responsibility that came with it. Therefore, instead of placing constraints on group work, students can be provided with a list of guidelines in the form of "checkboxes". These could include a recommended number of face-to-face meetings, approximate intermediary dates by which certain progress should be made and supporting documentation on how to use peer feedback best. This light scaffolding approach should nevertheless be complemented by the instructor's role as a "positive, proactive agent on behalf of group work" which was found to influence students' attitudes and perceived benefits of group work (Chapman and Van Auken, 2001). Instructors should run verbal checks on students' progress, allocate some time in seminars and lectures for questions, and remind students of the process and outcome of group work and their availability.

\section{Conclusion}

This article has examined the extent to which students work in groups collaboratively, the amount of scaffolding required to improve the efficiency of this process and the lessons drawn from it. Most importantly, students can work collaboratively within a group with minimum supervision and scaffolding, but benefit from appropriate guidelines on group work process, including encouragements to use blended learning and peer feedback appropriately, and having set in place formative assignments or intermediary feedback. This worked well in the context in which the instructor made herself available to discuss group work and checked verbally but regularly on progress. As Chapman and Van Auken (2001: 126) phrase it: "Instructors should 
express that the process is nearly as important as the output". Thus, based on the above, a good group work would maintain a balance between group members' self-regulatory behaviour and instructors' scaffold, the latter being mainly in the form of issuing guidelines and reminders, and running informal check-up on group progress.

The contribution this article makes to the literature is also twofold. It first focuses on the concept of collaborative as opposed to cooperative learning, including blended learning to peer feedback which can enhance the effectiveness of group work. A collaborative approach is deemed essential both to students through the way in which they participate in group work and develop their skills, and instructors who design group work tasks. Second, it focuses on scaffolding and argues that students can handle collaborative work and prefer less scaffolding than Stratling et al. suggest (2018) which can have an empowering and self-regulating effect on groups. Given that both pieces of research were conducted within different departments of the same university, a larger sample across different departments and universities may help us understand what accounts for the differences. While the sample of students used in this study is too small to generalise the results, considering that only 27 of 374 modules at the political science departments at the universities surveyed had a group work assessment component, this article can prove useful to those instructors who are considering adopting this pedagogical approach. Additionally, this article advises against regulatory strategies of solving conflict, i.e. when an individual student chooses to carry the weight of the task out of frustration (Volet and Mansfield, 2006), hence staff non-interference based on the idea that it replicates potentially real professional experiences or giving the students the option to work individually rather than in groups (Chapman and Van Auken, 2001). These approaches undermine the purpose of running group work and the benefits that can be extracted from it, reinforcing instead group assessment as a superficial diversification of assessment methods on the curriculum, rather than as a practical tool of enhancing group skills. The focus should therefore not be only on the 
outcome, but on the process and the skills acquired throughout it. Group self-regulation and minimal scaffolding can achieve this objective.

Group work requires an effective design and guidance at the initial stage of the project, but it does not need to become burdensome or time consuming. The preconceived concerns that often both lecturers and students hold towards group work can be tackled through pedagogical sessions for staff, and by better promoting the benefits of it to students and dissuading their concerns about low grade achievement in module handbooks and proforma. Group work can be a valuable experience for students and an efficient assessment method for staff. 


\section{References}

Aycock, A., Granham, C. and Kaleta, R. (2002) 'Lessons Learned from the Hybrid Course Project', Teaching Scholars Forum 8 (6).

Barkley, E., Major, C., and Cross, P. (2014) Collaborative Learning Techniques : A Handbook for College Faculty, San Francisco: John Wiley \& Sons.

Beaumont, C., O’Doherty, M. and Shannon, L. (2011) 'Reconceptualising assessment feedback: A key to improving student learning?' Studies in Higher Education 36(6): 671-687.

Bonanno, H., Jones, J. and English, L. (1998) 'Improving Group Satisfaction: making groups work in a first-year undergraduate course', Teaching in Higher Education 3 (3): 365382.

Bourner, J., Hughes, M., and Bourner, T. (2001) 'First-year undergraduate experiences of group project work', Assessment and Evaluation in Higher Education, 26(1): 19-39.

Cappelli, P. and Neumark, D. (2001) 'Do 'High-Performance' Work Practices Improve Establishment-Level Outcomes?', Industrial and Labour Relations Review 54 (4): 737-775.

Chapman, K. and van Auken, S. (2001) 'Creating Positive Group Project Experiences: An Examination of the Role of the Instructor on Students' Perceptions of Group Projects', Journal of Marketing Education 23 (2): 117-127.

Colbeck, C., Campbell, S. and Bjorklund, S. (2000) 'Grouping in the Dark: What College Students Learn from Group Projects', The Journal of Higher Education 71 (1): 60-83.

Connery, B. (1988) 'Group Work and Collaborative Writing'. Teaching at Davis, 14(1), p. 24. (Publication of the Teaching Resources Center, University of California at Davis)

Curşeu, P., Janssen, S. and Raab, J. (2012) 'Connecting the dots: social network structure, conflict, and group cognitive complexity’, Higher Education 63 (5): 621-629.

Cumming, J. (2010) 'Student-Initiated Group Management Strategies for More Effective and Enjoyable Groupwork Experiences', Journal of Hospitality, Leisure, Sport, \& Tourism Education 9.

Cumming J., Woodcock C., Cooley S., Holland, M. and Burns, V. (2015) Development and validation of the groupwork skills questionnaire (GSQ) for higher education, Assessment \& Evaluation in Higher Education, 40(7): 988-1001

Dolmans, D., Wolfhagen, I., van der Vleuten, C., and Wijnen, W. (2001) 'Solving problems with groupwork in problem-based learning: Hold on to the philosophy', Medical Education, 35(9), 884-889.

Erez, A. and LePine, J. and Elms, H. (2002) 'Effects of rotated leadership and peer evaluation on the functioning and effectiveness of self-managed teams: A quasi-experiment', Personnel Psychology 55 (4): 929-948. 
Felder, R. and Brent, R. (2001) 'Effective strategies for cooperative learning', Journal of Cooperation \& Collaboration in College Teaching, 10(2): 69-75.

Freeman, L., and Greenacre, L. (2010) 'An examination of socially destructive behaviors in group work', Journal of Marketing Education, 33(1): 5-17.

Garrison, R. and Anderson, T. (2003) E-Learning in the 21st century: A framework for research and practice, London: Routledge.

Garrison, R. and Kanuka, H. (2004) 'Blended learning: Uncovering its transformative potential in higher education - ScienceDirect', The Internet and Higher Education 7(2): 95-105.

Gibbs, G. (2009) 'The assessment of group work: Lessons from the literature', Centre for Excellence in Teaching and Learning in Higher Education, The Business School, Oxford Brookes University, available at http://owww.brookes.ac.uk/services/ocsld/group_work/brookes_groupwork_gibbs_de c09.pdf, accessed 2 February 2019.

Gokhale, A. (1995) 'Collaborative Learning Enhances Critical Thinking', Journal of Technology Education 7 (1).

Hämäläinen, R. and Vähäsantanen, K. (2011) 'Theoretical and pedagogical perspectives on orchestrating creativity and collaborative learning', Educational Research Review 6 (3).

Hansen, R. (2006) 'Benefits and Problems with Student Teams: Suggestions for Improving Team Projects', Journal of Education for Business 82 (1): 11-19.

Hattie, J. and Timperley, H. (2007) 'The Power of Feedback', Review of Educational Research 77 (1): 81-112.

Hobson, C., Strupeck, D., Griffin, A., Szostek, J., Rominger, A. (2014) 'Teaching MBA Students Teamwork and Team Leadership Skills: An Empirical Evaluation of a Classroom Educational Program, American Journal of Business Education', 7(3): 191-212.

Jaques, D. (2000) Learning in Groups: A Handbook for Improving Group Work, London: Routeldge.

Johnson, D. and Johnson, R. (1999) 'Making Cooperative Learning Work', Theory into Practice 38(2): 67-73.

Johnson, D., Johnson, R., and Smith, K. (2007) 'The state of cooperative learning in post secondary and professional settings’, Educational Psychology Review, 19: 15-29.

Jorn, L. and Duin, A. (1992) 'Information Technology and the Collaborative Writing Process in the Classroom', The Bulletin of the Association for Business Communication 55 (4): 13-20.

Kassop, M. (2003) 'Ten Ways Online Learning Matches, or Surpasses, Face-to-Face Learning', Technology Source 6. 
Kim, M. and Kannafin, M. (2011) Scaffolding problem solving in technology-enhanced learning environments (TELEs): Bridging research and theory with practice Computers \& Education, 56(2): 403-417.

Knight, J. (2004) 'Comparison of student perception and performance in individual and group assessments in practical classes', Journal of Geography in Higher Education 28 (1): 63-81.

Koppenhaver, G. and Shrader, C. (2003) 'Structuring the classroom for performance: Cooperative learning with instructor-assigned teams', Decision Sciences Journal of Innovative Education 1: 1-21.

Livingstone, D. and Lynch, K. (2000) 'Group Project Work and Student-centred Active Learning: two different experiences', Studies in Higher Education 25 (3): 325-345.

Lookatch, R. (1996) 'Collaborative learning and multimedia', Tech Trends 41 (4): 27-31.

Madge, C., Meek, J. and Wellens, J. (2009) 'Facebook, social integration and informal learning at university: "It is more for socialising and talking to friends about work than for actually doing work", Learning, Media and Technology 34 (2): 141-155.

Maguire, S., and Edmondson, S. (2001) 'Student evaluations and assessment of group projects', Journal of Geography in Higher Education, 25(2): 233-240.

Maiden, B., and B. Perry (2011) 'Dealing with Free-riders in Assessed Groupwork: Results from a Study at a UK University', Assessment \& Evaluation in Higher Education, 36: $451-464$.

Marks, M. and O'Connor, A. (2013) 'Understanding Students' Attitudes About Group Work: What Does This Suggest for Instructors of Business?', Journal of Education for Business 88 (3): 147-158.

Maybin, J., Mercer, N. and Stierer, B. (1992) “'Scaffolding': learning in the classroom”. In: Norman, Kate (ed.), Thinking Voices: The work of the National Oracy Project. London: Hodder \& Stoughton, pp.186-195.

Mello, J. (1993) 'Improving Individual Member Accountability in Small Work Group Settings', Journal of Management Education 17 (2): 253-59.

Meyer, K. (2003) 'Face-To-Face Versus Threaded Discussions: The Role of Time and Higher-Order Thinking'. Online Learning Journal 7 (3): 55-65.

Michaelsen, L. (1992) 'Team Learning: A Comprehensive Approach for Harnessing the Power of Small Groups in Higher Education', To Improve the Academy 11 (1): 107122.

Michaelsen, L. (1994) 'Classroom organization and management: Making a case for the small-group option' in K. Prichard and R. Sawyer (eds.), Handbook of college teaching: Theory and applications. Westport, CT: Greenwood, pp.139-155. 
Oakley, B. and Brent, R. and Felder, R. (2004) 'Turning student groups into effective teams', Journal of Student Centered Learning 2 (1): 9-34.

Oh, E. and Lim, D. (2005) 'Cross Relationships between Cognitive Styles and Learner Variables in Online Learning Environment', Journal of Interactive Online Learning 4(1): 53-66.

Osmond, J. and Roed, J. (2010) 'Sometimes it means more work: Student perceptions of group work in a mixed cultural setting' in E. Jones (ed.), Internationalisation and the student voice, New York: Routledge, pp.113-124.

Pauli, R., Mohiyeddini, C. and Bray, D. (2008) 'Individual differences in negative group work experiences in collaborative student learning', Educational Psychology 28 (1): 47-58.

Perkins, G. (2018) 'A Cultural Political Economy of the Employability Discourse in the UK', BA Dissertation, School of Politics and Global Affairs, University of Durham.

Peterson, P. and Janicki, T. and Swing, S. (1981) 'Ability $\times$ Treatment Interaction Effects on Children's Learning in Large-group and Small-group Approaches', American Educational Research Journal 18 (4): 453-473.

Pfaff, E. and Huddleston, P. (2003) 'Does It Matter if I Hate Teamwork? What Impacts Student Attitudes toward Teamwork', Journal of Marketing Education 25 (1): 37-45.

Renshaw, P. (2013) 'The social cultural and emotional dimensions of scaffolding, Learning, Culture and Social Interaction', 2(1): 56-60.

Rafferty, P. (2013) 'Group Work in the MBA Classroom: Improving Pedagogical Practice and Maximizing Positive Outcomes with Part-Time MBA Students', Journal of Management Education 37 (5): 623-650.

Rose, D. and Meyer, A. (2002) Teaching Every Student in the Digital Age: Universal Design for Learning. Alexandria, VA: ASCD.

Ruel, G., Bastiaans, N., and Nauta, A. (2003) 'Free riding and team performance in project education’, International Journal of Management Education, 3(1): 26-38.

Ryan, R. and Deci, E. (2000) 'Intrinsic and Extrinsic Motivations: Classic Definitions and New Directions', Contemporary Educational Psychology 25 (1): 54-67.

Schedlitzki, D. and Witney, D. (2014) 'Self-directed learning on a full-time MBA: A cautionary tale’, The International Journal of Management Education 12: 203-211.

Smith, K. (1996) 'Cooperative learning: Making "group work' work”, New Directions for Teaching and Learning (67): 71-82.

Stratling, R. and McMurray, R. (2018) 'Excellent group work by design: Developing collaborative life-long learning through scaffolding', British Academy of Management Conference; 4-6 September 2018; Bristol, United Kingdom.

The Quality Assurance Agency for Higher Education (2015) Subject Benchmark Statement: 
Politics and International Relations, available at:

http://www.qaa.ac.uk/docs/qaa/subject-benchmark-statements/sbs-politics15.pdf?sfvrsn=ee95f781_14, accessed 25 January 2019.

Tieman, R. (2012) ‘From teamwork to collaboration', Financial Times, 12 March.

Volet, S. and Mansfield, C. (2006) 'Group work at university: significance of personal goals in the regulation strategies of students with positive and negative appraisals', Higher Education Research \& Development 25 (4): 341-356.

Vygotsky, L. (1978) Mind in Society-the development of higher psychological processes. Cambridge: Harvard University Press.

Walker, A. (2001) 'British Psychology Students' Perceptions of Group-Work and Peer Assessment', Psychology Learning \& Teaching 1 (1): 28-36.

Webb, N., Nemer, K. and Zuniga, S. (2002) 'Short Circuits or Superconductors? Effects of Group Composition on High-Achieving Students' Science Assessment Performance', American Educational Research Journal 39 (4): 943-989.

Webb, N. and Cullian, L. (1983) 'Group Interaction and Achievement in Small Groups: Stability Over Time’, American Educational Research Journal 20 (3): 411-423.

Williams, H. and Smith, N. (2017) "Feedback: critiquing practice, moving forward", European Political Science, 16 (2): 159-172.

Dr. Oana Burcu is an Assistant Professor in Contemporary Chinese Studies in the School of Politics and International Relations and Fellow of the Asia Research Institute, at University of Nottingham, UK. Previously she taught East Asian politics at University of Durham. She has a master's in international studies on Contemporary Asia Pacific from University of Birmingham and a PhD in Politics and International Relations from University of Nottingham. Her interests lie particularly in Chinese nationalism, China's foreign policy and Asia-Pacific security. She has worked and conducted fieldwork in China for over two years and was a visiting fellow at Fudan University, China. 